\title{
The problems and countermeasures of humanistic quality education in
}

\section{higher vocational colleges}

\author{
Hong Chen ${ }^{1, \mathrm{a}}$, Chun-Yan Teng ${ }^{1, \mathrm{~b}}$, Hong-Hui Deng ${ }^{1, \mathrm{c}}$, Min Liu $^{1, \mathrm{~d}},{ }^{\text {,Chao }} \mathrm{Li}^{1, \mathrm{e}}$, \\ Xia Yuan ${ }^{1, f}$, Jing-Jing Yang ${ }^{1, g}$ \\ ${ }^{1}$ Guang'an vocational and technical college, Guang'an 638000,China

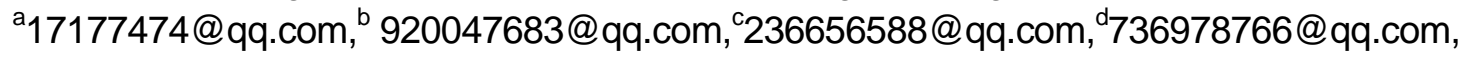 \\ e45030547@qq.com, ${ }^{f} 81627805 @ q q . c o m,{ }^{9} 93682417 @ q q . c o m$
}

Keywords: higher vocational college, humanistic quality education, problems,countermeasures

\begin{abstract}
With the upgrading and adjustment of the economic industrial structure,employer continuously improve the quality requirements of the higher vocational college graduates. Students in higher vocational colleges should be advanced technology applied talents with good cultural and moral cultivation. The current situation of humanistic quality education in higher vocational colleges is not optimistic, and the phenomenon of "heavy skill, light humanity" is widespreaded. In order to improve the professionalism of graduates and humanity education,some methods are used,such as these methods of clearing objectives of higher vocational education, seting up reasonable teaching content, innovating teaching methods and strengthening the construction of teaching staff and so on. The humanistic quality education in higher vocational colleges is improved greatly through these countermeasures.
\end{abstract}

\section{Introduction}

The students in higher vocational colleges are the applied talents who have good cultural qualities, moral attain and high-technology. Therefore, we must pay attention to the humanistic quality education in the course of professional and technical education in higher vocational colleges. It similar to ordinary colleges and universities, humanistic quality education in higher vocational schools includes humanistic knowledge, humanistic thought and humanistic spirit and so on.It aims at trainning college students to form their sound outlook on the world, life and values[1]. It different from ordinary colleges and universities that the humanistic quality education in higher vocational schools emphasizes to train college students' professional spirit.

At present,the status of humanistic quality education in higher vocational schools is not optimistic,the phenomenon of paying attention to skills and despising the humanities is widely exist[2]. Humanistic quality-oriented education courses and teachers are long neglected,their status are low,courses are little and the teaching methods can't keep up with the development of the times. The humanistic quality of higher vocational colleges students is relatively low,it leads to college students in the study period and graduation work, there have been a large number of non professional technical problems[3]. These problems have attracted more and more attention of higher vocational colleges[4].These higher vocational colleges start from the school of humanities quality education and research how to cultivate a new era of higher vocational college Students in the new era of mental sound, humanistic spirit and harmonious development.

\section{The present situation of education}

From the recent survey data and the situation that author interview a number of higher vocational college teachers and students,it can conclude that the humanistic quality education in higher vocational 
colleges has been strengthened. More and more college students demand for humanistic quality education , more and more attention is attached to the development of humanistic quality education in schools[5]. But at the same time the problem is also very prominent, specific performance is in the following aspects.

\section{1 low status}

Although higher vocational colleges have put forward the aim is to cultivate high quality worker. But in fact the humanities quality education has not been paid enough attention in higher vocational colleges if it compare to the professional and technical education. School administrators pay more attention to the skills of university students education, they organize and participate in various skills competition. Examination skills is the focus of the work of higher vocational colleges, they become the main conditions of the appraised incentives. But the humanities quality education is the ornament of the higher vocational education. Accordings to the way of knowledge education to carry out education, it often be forced to set up some courses and carry out some activities, the courses and activities are in the edge of the school work, they lack adequate policy and financial support and the status of humanistic quality education in higher vocational colleges is very low.

\section{2 less course}

Humanistic knowledge and humanistic thought and humanistic spirit culture need to be completed through appropriate education curriculum system, but most vocational colleges carry out humanities education just through a course or a few lectures, these methods lack of plan that organize teaching according to the education system of humanistic quality, especially in polytechnic colleges of professional.it difficult to get the related courses with humanistic quality education, "Two Courses" is used to replace the humanistic quality education, it is difficult to meet the demand for contemporary college students to humanistic quality education.

2.3 old method

As the Internet gradually comes into the life of the college students in the age of mobile Internet, information network has become the main way of education, but most full-time universities is not sensitive to the combination for science and education especially in vocational colleges. They does not make full use of network information, both professional skills and humanistic quality education is still following the traditional way of education, they did not play the advantages of network education. In the survey of the higher vocational colleges which have already carried out the network humanistic quality education, the education resources that the school through the network provides the humanities quality lack the attraction. They just to provide some articles on the network, the content is same and the means and form are single.

\section{Analysis of causes}

\section{1 the influence of school's utilitarianism}

Higher vocational education is accompanied by appearing in the modern industrial production, it is bound to reflect the needs of social and economic development, and it takes the initiative to adapt the development. Higher vocational education is carried out from the angle of industrial society needs. At present, China's economic construction is facing a serious shortage of high-tech talents, the lack of humanistic quality education caused by the one-sided understanding of the technology in higher vocational colleges. Schools only emphasize the function of vocational education for the development of social reality. the skill level of education is emphasized, and the training of spirit for people is ignored. The position of humanistic quality education has been marginalized.

\section{2 teachers' education ability is insufficient}

Most of the higher vocational colleges are upgraded from technical secondary schools. Due to the scale and strength of the schools, there is no such as the general institutions of higher education, such as the departments of literature, history and philosophy. It is one of the objective factors to restrict the effect of education, which is the lack of the humanities curriculum and the resources of humanities quality 
education.

In dealing with the distinctive characteristics of higher vocational colleges, most of the professional teachers are limited by their knowledge structure and cultural quality. In the course of teaching of professional theoretical education, students are not concerned about the professional development of science and technology which relate to the economic, environmental, legal, moral and other cultural issues. Because of the lack of humanistic knowledge and humanistic thought and humanistic spirit, it is difficult to play the role of the main force of humanistic quality education in higher vocational colleges. At the same time, the higher vocational colleges almost have no specialized teachers in the humanities quality education, there is no special forces to study and promote the humanistic quality education. Campus culture is filled by the argument of "professional and technical first" . It is difficult for the teachers to infiltrate the humanistic quality education and carry out the humanistic quality education under this circumstance.

3.3 students themselves are weak

From the basic quality of students in higher vocational colleges and professional atmosphere of higher vocational colleges, the humanistic quality education has a large gap with the ordinary universities. Higher Vocational College Students' cultural quality is relatively low, and the foundation of humanistic quality is relatively weak. Schools more emphasis on professional skills training, as a result,humanities quality study is relatively not concentrated. Survey shows that the proportion which higher vocational college students often go to the library to read is less than $40 \%$, most students only go to the library occasionally, or even do not go to the library. The school's humanistic quality education activity coverage is not more than $60 \%$. Students who can participate in the humanities quality education activities for more than two times per semester are less than $30 \%$. The interests of higher vocational college Students' humanistic quality education are affected by these gaps directly, and their ability to accept humanistic quality education and improve their humanistic quality are affected.

\section{Improvement of humanistic quality education in higher vocational colleges}

The improvement of humanistic quality education in higher vocational colleges should be based on the actual situation. It needs to establish a clear educational objective according to the characteristics and training objectives of the school, educational content should be set up reasonable, and should be in line with the times. Education ways should be developed creative, and it should adapt to the changing needs of students. Teachers' humanistic quality should be strengthened. The current situation of higher vocational colleges humanistic quality education should be improved from all aspects,as a result, the implementation of humanistic quality education will be promoted.

4.1 clear educational goals

The higher vocational colleges must set up the clear goal of humanistic quality education,they should overcome the education concept of "professional first". In order to obtain the basic education resources for the humanities quality education, the humanities quality education and the professional technology education must be placed in an equal position.

4.2 set up educational content

The teaching mode of "2+1" in higher vocational colleges has resulted in only two years of study in higher vocational college, which is far lower than that of ordinary universities. Therefore, higher vocational colleges should strengthen the education efficiency of the limited humanities quality education curriculum and the humanistic quality education in the professional and technical education.

4.3 innovative education method

Humanities quality education is not a professional skill course, teaching methods should be innovated to improve their own attractiveness and enhance the effect of humanistic quality education.

4.3.1 improve teaching method

The course of humanities quality education should give full play to the subjective initiative of college students.The teaching methods of the modern education idea such as the heuristic, the discussion 
type, the inquiry type, the case type and so on should be used. The content of humanistic quality education will be transfered in the way of humanity, and the goal that humanistic quality education will reach.

\subsection{2 enrich teaching methods}

In the course of humanistic quality education, the modern information transmission means of all kinds of multimedia should be integrated. Extensive and profound knowledge of the humanities is showed through a variety of forms. Humanities quality education is easier than the professional technology education to carry out through network. The characteristics of the network is fast, convenient and easy to interact.,teachers and students are full contacted to transfer the concept of humanistic quality education.

4.3.3 strengthen the construction of campus culture

The campus culture is an effective way to improve the humanistic quality of higher vocational college Students in higher vocational colleges. It is the form which through college students' self education to carry out humanistic quality education, it has unique advantages that can not be replaced by other forms.

Student association is a student's self governance organization, higher vocational colleges should support and encourage students' associations to carry out humanistic quality education activities. The school's own professional characteristics and advantages should be connected, the current social hot spots and focus of the problem as an opportunity also should be connected , the school carry out the corresponding theme activities under the guidance. The patriotic enthusiasm, the sense of responsibility and the collective spirit of the young students will be inspired.

4.3.4 promote the cultural exchange between school and enterprise

Vocational training objectives of higher vocational colleges need to be in line with the enterprise, the humanistic quality education in higher vocational colleges also needs to be in line with the enterprise culture construction. The cultural differences between the humanistic quality education and the enterprise culture is narrowed through school and enterprise cooperation.These methods can lead college students to experience the integrity, professionalism and other corporate cultural spirit in the study period.

\section{Construction of teaching staff}

\section{1 improve teachers' humanistic quality}

In today's information society, teachers have changed from the presenter into a leader, they not only present knowledge skills to the students but also lead students to learn and innovate. Higher vocational teachers in teaching can not only be limited to the simple teaching of knowledge and skills,they should penetrate the humanistic quality education into professional skills teaching. At the same time to improve the students' professional skills, cultivate their humanistic thinking and humanistic spirit. Higher vocational teachers should develop their own humanistic knowledge and improve the personal humanistic quality and illuminate the humanistic quality of university students with the light of their own.

\section{2 strengthen the training of teachers' humanistic quality}

Compared with ordinary colleges and universities, higher vocational colleges have almost no special education on humanistic quality education. From the current practical point of view, we must combine the introduction of talent and strengthen the training,especially strengthen the training oriented. Training is divided into two aspects, one is the professional training of humanistic quality education for full-time teachers,the aim is to improve their professional ability and professional quality.The second is to carry out general humanities quality education and training for all teachers to improve the humanities quality. 


\section{Summary}

"Professional and technical standard" has led to the emergence of a large number of "non mainstream" phenomenon in higher vocational college students. Humanistic quality education that should be Strengthened has become an urgent problem to be solved in higher vocational colleges. Higher vocational colleges must change from "heavy skill" to "equal emphasis on skill and humanities". The connotation construction of humanistic quality education should be strengthened. Higher vocational colleges should be combined with the schools of their own characteristics to cultivate students' professional ethics and professionalism,as a result,the students can form a correct world outlook, outlook on life and value concept.The final aim is to cultivate talents with good cultural and moral cultivation of higher technical application.

fund project: the humanities and social science research project of sichuan provincial department of education " research on current situation and countermeasures of humanistic quality education in higher vocational colleges"

item number:16SB0364

\section{References}

[1] jingjing Jie. the basic contents and effective ways of life education in higher vocational colleges[D]. qufu: qufu normal university,2011:4-5.

[2]lijing Jia. belief crisis of contemporary Chinese people and its resolution[D].jinan: shandong university,2012:2-3

[3]daimin Xu. reflections on the ideological education of college students' patriotism[J]. journal of tai'an institute of education of dai,2008(3):9-25

[4]yuejin Rao. a review on the study of students' views in China in recent years[J]. journal of jiangxi institute of education,2010,31(3):10-15

[5]guiping Liu. exploration of humanistic quality education in higher vocational colleges[J]. journal of ningbo polytechnic,2011(6):33-35 